\title{
Benign Leptospirosis: First Reported Outbreak in British Isles due to Strains Belonging to the Hebdomadis Serogroup of Leptospira interrogans
}

\author{
ALEX SAKULA,* M.D., M.R.C.P. ; WILLIAM MOORE, $†$ M.B., D.T.M.\&H., D.P.H.
}

\author{
Brit. med.F., 1969, 1, 226-228
}

Summary: The clinical and epidemiological features $N$ associated with the first reported outbreak in the British Isles of benign anicteric leptospirosis, due to strains belonging to the hebdomadis subgroup, are described. Four cowherdsmen working in two dairy farms in Surrey developed a febrile illness which was not associated with jaundice, but aseptic meningitis was a feature. Microscopic agglutination tests with formolized antigen suspensions revealed a significant rise in the agglutinin titres against various serotypes belonging to the hebdomadis serogroup of Leptospira interrogans. The probable source was eventually traced to the cattle, which showed serological evidence of infection with the same serogroup.

\section{Introduction}

Since Adolf Weil (1886) first wrote his classical description of the variety of infectious jaundice which now bears his name, and Inada et al. (1916) discovered the cause to be Leptospira icterohaemorrhagiae, the world-wide distribution of leptospiral infections, both in animals and in man, has become apparent. In addition to typical Weil's disease, with its hepatic and renal involvement, and carrying a serious morbidity and mortality, many other varieties of leptospirosis are now known to occur, which produce less severe illness in man and are designated benign leptospirosis. These cases of leptospirosis are due to leptospiral serotypes, of which approximately 130 (grouped together into 16 serogroups) have now been differentiated (W.H.O., 1967 ; Turner, 1967). The first leptospira to be distinguished from $L$. icterohaemorrhagiae was by Ido et al. (1918), who investigated the seven-day fever " nanukayami" which occurred in Southern Japan (" seven-day fever of Japan "), the symptoms being those of atypical anicteric Weil's disease. The causative organism was designated $L$. hebdomadis, and was found to spread to man from infected field mice. Since then $L$. hebdomadis infection in man has been described in various countries in the Orient, but only extremely rarely in Europe, reports of occasional cases having come from Denmark (Petersen and Christensen, 1939), Switzerland (Gsell, 1952), Germany (Marcuse and Eggert, 1953 ; Mochmann et al., 1956), Rumania (Grigore and Trifan, 1963), and Poland (Mierzejewska et al., 1967). To date there have been no published reports of human infection by $L$. hebdomadis in the British Isles.

We describe here the clinical features of four cases of leptospirosis which on serological evidence were considered to have been caused by strains belonging to the hebdomadis subgroup. These occurred in the summer of 1968 among cowherdsmen working in two dairy farms (named here A and B) in Surrey, together with the epidemiological investigations which were carried out to discover the cause of the outbreak.

\section{Case 1}

A cowherdsman aged 26 at farm A became ill on 8 June 1968 with pyrexia (temperature $102.4^{\circ} \mathrm{F} . ; 39.1^{\circ} \mathrm{C}$.), shivering, sweats, headache, and myalgia. The next day he developed sore throat, cough, slightly blood-stained sputum, dizziness, and photophobia, and the headache persisted. He was admitted to hospital on 12 June, when he complained of frontal headache, sore throat, and vomiting. On clinical examination he was pyrexial (temperature $103.4^{\circ} \mathrm{F}$.; $39.7^{\circ} \mathrm{C}$.), and there was only a mild pharyngitis. $\mathrm{He}$ was not jaundiced, and there was no meningism. Throat swab cultured beta-haemolytic streptococci. Abnormal findings on investigation were present in the urine, which contained protein + , and scanty hyaline casts; culture was sterile. Blood was taken for leptospiral agglutinations on 13 June and the dominant reactions were obtained with antigens (formolized) representing the hebdomadis serogroup (highest titre 1,000 with hebdomadis). Serum obtained on 28 June gave a similar pattern of reactions with rises in titre ranging between one and three dilution steps with suspensions of hebdomadis, worsfoldi, sejroe (Mallersdorf II), medanensis, wolffii, and hardjo, in particular.

On report of beta-haemolytic streptococci in the throat swab, treatment with penicillin was begun on 13 June by injection, 1 mega unit six-hourly for five days, then oral penicillin $250 \mathrm{mg}$. q.i.d. for one week. There was a rapid subsidence of symptoms, and by 16 June he was apyrexial.

\section{Case 2}

A cowherdsman aged 21 at farm A became ill on 23 June 1968 with pyrexia (temperature $102^{\circ} \mathrm{F} . ; 38.9^{\circ} \mathrm{C}$.), sore throat, headache, myalgia, and vomiting. On 25 June he felt better and was apyrexial, but on the 27 th he complained of headache, and on the 28th he was found to have neck stiffness and was admitted to hospital. On clinical examination he was pyrexial (temperature $100^{\circ} \mathrm{F} . ; 37.8^{\circ} \mathrm{C}$.), pulse 64 , and there was evidence of meningism ; he was not jaundiced, though the liver edge could just be felt. Lumbar puncture revealed a clear colourless cerebrospinal fluid at a pressure of $200 \mathrm{~mm}$., which was reported to contain protein 40 mg./100 ml., 213 cells/cu. mm. (polymorphs $32 \%$, lymphocytes $68 \%$ ), glucose $60 \mathrm{mg} . / 100 \mathrm{ml}$; ; no organisms were seen, and culture was sterile. Other investigations gave results within normal limits, except for a serum alanine aminotransferase, which was raised to 84 units $/ \mathrm{ml}$. Blood culture was sterile.

A provisional diagnosis of leptospirosis was confirmed by serum agglutination tests for leptospirosis ; though these were negative on 24 June they showed dominant reactions with serotypes of the hebdomadis subgroup on 1 July at titres as high as 1,000 (hebdomadis and hardjo).

He was not treated with penicillin, and his condition returned to normal after 48 hours; he then remained well.

\section{Case 3}

A cowherdsman aged 20 at farm A became ill on 8 July with pyrexia, sweats, headache, fatigue, and myalgia. He was admitted to hospital on 9 July, and then had a generalized epileptic convulsion. Headache, vomiting, and photophobia were also present. On clinical examination he was pyrexial (temperature $103.4^{\circ} \mathrm{F}$.; $39.7^{\circ} \mathrm{C}$.), pulse 120 . There were signs of meningism. He was not jaundiced, but the liver edge was just palpable. Lumbar puncture revealed normal cerebrospinal fluid. The results of other investigations were normal, apart from a serum alanine aminotransferase raised to 147 units/ml. and a leucocytosis (W.B.C. $15,400 /$ cu. mm. ; polymorphs $77 \%$, lymphocytes $2.1 \%$, monocytes $1 \%$, basophils $1 \%$ ). 
On admission a provisional diagnosis of leptospirosis was made and this was subsequently confirmed by the serum agglutination tests for leptospirosis, these being negative on 9 July, but becoming positive on 15 July to the $L$. hebdomadis serogroup to a titre of 100.

He was treated with penicillin by injection of 1 mega unit sixhourly for two days, and then penicillin-V $250 \mathrm{mg}$. q.i.d. for three days. The illness subsided after 24 hours.

\section{Case 4}

A cowherdsman aged 23 at Farm B became ill on 15 August with pyrexia, headache, and malaise. On the following day he was still pyrexial, and a diagnosis of influenza was made. He continued to sweat profusely, the headache was worse, and he developed a slight cough. Because of the clinical suspicion of leptospirosis, blood was taken on 18 August for leptospiral agglutinations, and treatment was begun with penicillin by injection of 1 mega unit b.d. Next day he felt much better, but a day later his temperature rose again to $100^{\circ} \mathrm{F}$. $\left(37.8^{\circ} \mathrm{C}.\right)$, and on 21 August he was admitted to hospital.

On clinical examination he was pyrexial (temperature $101^{\circ} \mathrm{F}$; $38.3^{\circ} \mathrm{C}$.), but otherwise nothing abnormal was found. $\mathrm{He}$ was not jaundiced and there was no meningism. Nevertheless on lumbar puncture the cerebrospinal fluid was clear and colourless but the pressure was raised to $200 \mathrm{~mm}$., and analysis showed the cells to have reached $230 / \mathrm{cu} . \mathrm{mm}$. (polymorphs $50 \%$, lymphocytes $50 \%$ ), protein $30 \mathrm{mg} . / \mathrm{ml}$., and glucose $84 \mathrm{mg} . / \mathrm{ml}$. Other investigations gave normal results, apart from a serum alanine aminotransferase which was raised to 66 units $/ \mathrm{ml}$. The agglutination screening test on the first serum (18 August) was negative at 1 in 10 . The second serum (26 August) reacted dominantly with serotypes of the hebdomadis serogroup at titres ranging between 100 and 3,000 (hardjo).

Treatment in hospital continued with penicillin-V $250 \mathrm{mg}$. q.i.d. for five days, and he soon responded, the temperature becoming normal by 24 August. When seen on 9 September, following his discharge from hospital, he had recovered completely.

\section{Clinical Features}

In all four cases the disease began with symptoms suggestive of an influenzal illness. Fever, sweats, and shivering were accompanied by headache, myalgia, sore throat, and cough (with blood-stained sputum in one case). In none of the cases did jaundice appear, though in three of the four there was a rise in the level of serum alanine aminotransferase, which rapidly returned to normal on recovery from the infection. Nor was there any evidence of serious renal involvement, only one case showing albumin and some hyaline casts. In three of the four cases the blood showed no leucocytosis. Rashes, conjunctivitis, lymphadenopathy, and splenomegaly were conspicuous by their absence.

The symptoms of meningeal irritation were predominant in Case 2, and the cerebrospinal fluid showed evidence of an aseptic meningitis with a mixed pleocytosis. It is of interest, however, that in Case 4, in which there was some headache but no obvious meningism, the cerebrospinal fluid also showed evidence of aseptic meningitis.

The diagnosis in Case 1 was initially obscure, and it was investigated thoroughly as a P.U.O., but in the subsequent cases the clinical index of suspicion was high and the diagnosis presented less difficulty. Confirmation of the diagnosis was obtained by examination of paired sera, which showed a rising titre of agglutination to antigen suspensions representing the hebdomadis subgroup. Attempts to isolate the strains were unsuccessful in all cases.

Treatment with penicillin led to rapid cure of the disease in three cases, but it is significant that in Case 2 (in which there was an aseptic meningitis) treatment with antibiotics was withheld, and there was a spontaneous remission of the disease.

\section{Epidemiological Investigation}

These four cases occurred in two farms. The first three men worked in farm A, which covered 450 acres (182 hectares), and contained 220 milking cows, 70 calves, and 45 heifers. The fourth man worked in farm $\mathrm{B}$, which covered 210 acres ( 85 hectares), and contained only 160 milking cows. The distance between the two farms was 15 miles $(24 \mathrm{~km}$.). The farmer who bought farm A two years previously was also the manager of farm B. There had been considerable movement of heifers and calves between the two farms, young calves from farm A being delivered in farm $B$, and then sent back.

When the first case was diagnosed at farm $A$ it was suspected that field-mice around the farm were probably the source of infection. The public health department was informed, and inquiries revealed that the men had become ill after sweeping and moving sacks of grain in the loft above the milking parlour, and it was thought that the infection had come from the urine of mice living there. Investigations were therefore initially concentrated on this area of the farm. The cows had been fed by pulling sacks in the loft towards chutes leading down to the cow stalls below. The whole area was very dusty, there was spilt grain on the floor, and mouse droppings were scattered over a wide area. On closer examination numerous places were seen where mice could live. It was decided to destroy all the mice, and a specialized firm was asked to assist. The whole area was sealed off and gas was used. The result, however, was disappointing, in that only a few mice were found, and it was considered unlikely that the milking parlour could have been the main site of infection.

Other parts of the farm, such as the rest room and a Dutch barn, were then examined in detail, still with the idea that the infection was coming from the urine of infected field mice, but with negative results. At this stage the manager of farm A, who previously had not been involved in milking, had to join the milking rota, and he became ill with pyrexia, malaise, and headaches. He was put off duty, was given a course of penicillin, and soon recovered. The owner of farm A (also the manager of farm B) was now forced to assist with the milking, and for the sake of the overall administration of the two farms it was decided to give him a prophylactic course of penicillin by injection, and he did not become ill. This sequence of events pointed all the more to the disease being associated with the specific work carried out by the cowherdsmen.

In the past farm $A$ had been mainly under cultivation with cereals, the hedges had been allowed to thicken, and the ditches were undisturbed. When the new owner took over two years previously he changed to a dairy herd. The land was heavy clay soil, flat, with a high water table, and the fields were sodden in heavy rain. This land was now drained and the hedges were pulled down or cut back. It was postulated that a large population of field rodents had then developed, and with their source of food decreased they moved to the farm. If these mice already maintained enzootic leptospiral infection, a rapid and large increase of non-immunes in the mouse population could result in a localized epizootic, and many more leptospires would then be shed in the animals' urine and the chance of accidental human contact and infection would be increased. The optimum conditions for leptospiral spread-warmth and moisture-were met in the summer of 1968, which was exceptionally wet in the south of England. The mode of transmission was postulated to be from the contaminated damp fields to the cows' hides, and when the men drove the cattle in for milking they would push and guide the animals and also wash the udders, and in this way their hands would be contaminated with the organisms.

The Infestation Control Laboratory of the Ministry of Agriculture sent a team to farm $A$, and rodents in the farm buildings and surrounding fields were trapped and killed. Mice which were trapped alive were sent to the Leptospirosis Reference Laboratory. However, the bacteriological investigations 
on these animals proved to be negative for leptospiral infection. The probable source of infection now pointed more and more to the cows themselves. Urine samples from a random number of cows on both farms proved to be negative for leptospirosis. However, blood taken from 20 random cows showed that in 15 the leptospiral agglutinations were positive with antigens representing the hebdomadis subgroup (serotypes mini and wolffii). Several unexplained abortions had occurred among the cattle in the past year. By chance, in August 1968 two cows aborted on farm B ; the foetuses and blood were examined, and agglutination tests with antigens representing the hebdomadis subgroup were found to be positive. This leptospiral infection of the cattle was not held to be necessarily responsible for the abortion. It was felt, however, that the cowherdsmen had been infected by direct contact with the infected cattle.

\section{Conclusion}

It would appear, therefore, that this small outbreak of four human cases of leptospirosis hebdomadis arose from direct contact with infected cattle, and not, as is more usual in leptospiral infection, from infected rodents or other animals or pets -for example, dogs in the case of infection with $L$. canicola. Evidence is accumulating that a high proportion of the cattle in the British Isles are infected with leptospires, though they may not necessarily show much clinical manifestation of this. At the present time leptospirosis in cattle is not a notifiable disease. Increasingly, human cases of benign leptospirosis are being reported in Europe, but so far there has been no previous report of an outbreak in the British Isles of infection with L. hebdomadis in man, though sporadic positive serological tests are occasionally met with in this country (L. H. Turner, personal communication, 1968). As from 1 October 1968 leptospirosis has become a notifiable disease in man under the Public Health (Infectious Diseases) Regulations, 1968. The true incidence of benign leptospirosis will henceforth be known more accurately.

Many cases of leptospirosis are not diagnosed at the present rime, since the condition is not considered. Short fevers, of the P.U.O. type, without jaundice but with headache and meningism (due to aseptic meningitis) may well be examples of benign leptospirosis, and this diagnosis must be considered, especially if there is any possibility of infection with the organism.

Preventive measures consist essentially in the destruction of rodents and the improvement of personal and environmental hygiene of persons potentially exposed to infection either at work or in their leisure pursuits.

We thank Dr. J. P. Mackєy, consultant bacteriologist, Redhill Group Pathological Laboratory, and Dr. L. H. Turner, director, Leptospirosis Reference Laboratory, for their co-operation in the bacteriological and serologica! investigations of these cases. We also thank Dr. K. Heber and Dr. H. A. Leggett for allowing us to quote Cases 1 and 3 respectively.

Copies of reprints may be obtained from Dr. A. Sakula.

\section{REFERENCES}

Grigore, R., and Trifan, G. (1963). Microbiol. Parazitol. Epidemiol., 8, 45. $\mathrm{O}$. (1952). Leptospirosen. Berne.

Gsell, O. (1952). Leptospirosen. Berne.

Inada, R., Ido, Y., Hoki, R., Kaneko, R., and Ito, H. (1916). 7. exp. Med., 23, 377 .

Marcuse, K., and Eggert, E. (1953). Dtsch. med. Wschr., 78, 1360. Mierzejewska, I., Radomińska, I., and Cybulska, M. (1967). Pol. Tyg. lek., 22, 760 .

Mochmann, H., Kathe, J., and Kuppi, H. (1956). Z. Immun.-Forsch., 113, 319 .

Petersen, C. B., and Christensen, H. I. (1939). Ugeskr. Lag., $101,697$.

Turner, L. H. (1967). Trans. roy. Soc. trop. Med. Hyg., 61, 842.

Weil, A. (1886). Dtsch. Arch. klin. Med., 39, 209.

W.H.O. (1967). Wld Hlth Org. techn. Rep. Ser. 380.

\title{
Leptospirosis in Human Pregnancy followed by Death of the Foetus
}

\author{
JOYCE D. COGHLAN,* B.SC., PH.D. ; A. D. BAIN, $\dagger$ M.D., M.C.PATH.
}

Brit. med.F., 1969, 1, 228-230

\begin{abstract}
Summary : An attack of leptospirosis due to serotype canicola in a pregnant woman was followed in the convalescent period by death of the foetus. Previous cases of this nature are reviewed. In certain areas where leptospirosis is known to exist among the animal population early recognition and treatment of human cases is advised, especially when they occur during pregnancy.
\end{abstract}

\section{Introduction}

The tendency to abortion as a complication of human leptospirosis has been referred to in a number of publications. For example, cases of abortion during an attack of canicola fever were described in Germany by Cramer and Wadulla (1950) and by Bleier and Lechtken (quoted by Kathe and Mochmann, 1967); and Alston and Broom (1958) quoted a report by Hiyeda in Japan on a case of abortion of a 4-month-old foetus

\footnotetext{
* Lecturer, Department of Bacteriology, University of Edinburgh, Edinburgh 8.

† Consultant Pathologist, Royal Hospital for Sick Children, Edinburgh 9.
}

by a woman suffering from Weil's disease. These workers, however, failed to isolate the leptospires from the foetus, nor were they able to demonstrate them in histological sections of foetal tissues, so it was not possible to say whether the abortions occurred merely as a result of the maternal condition or whether the organisms had actually penetrated the placenta, with subsequent infection of the foetus, and that foetal infection resulted in foetal death.

Proof that intrauterine infection of the human foetus can occur was given by the work of Chung et al. (1963) in China. These workers isolated leptospires from the liver and kidney of a 5-month-old foetus aborted by a patient suffering from leptospirosis due to serotype kasman. They also isolated serotype bovis from the amniotic fluid, placenta, and cord blood of a leptospirosis patient whose baby, delivered at full term, appeared to suffer from and was successfully treated for a mild attack of congenital leptospirosis from the second to the twelfth day after birth.

Chung et al. also referred to the high rate of abortion and miscarriage that occurs when leptospirosis is acquired during pregnancy in certain rice-growing areas of China, where pre- 